\title{
Comparison of freeze drying and spray drying to obtain porous nanostructured granules
}

\section{from nanosized suspensions}

Mónica Vicent ${ }^{(1)}$, Enrique Sánchez ${ }^{(1)}$, Tamara Molina ${ }^{(2)}, \mathrm{M}^{\mathrm{a}}$ Isabel Nieto ${ }^{(2)}$, Rodrigo Moreno ${ }^{(2)}$

(1) Instituto de Tecnología Cerámica (ITC). Asociación de Investigación de las Industrias Cerámicas (AICE). Universitat Jaume I (UJI). Castellón, Spain.

${ }^{(2)}$ Instituto de Cerámica y Vidrio (ICV). CSIC. Madrid, Spain.

\begin{abstract}
Spray drying and freeze drying are well established granulation processes for submicron and micron sized particles. In recent years, granulation of nanoparticle suspensions is receiving increased interest for the production of nanostructured materials.

In this work the spray drying and freeze drying of different nanosized ceramic materials and the physicochemical characteristics of the obtained granules (size distribution, morphology, surface area, porosity, and flow parameters) are studied. Commercial colloidal suspensions of alumina and titania were studied, as well as a mixture of both with a relative weight ratio of 87/13. On one hand, the influence of temperature, pressure and nozzle diameter on the morphology and characteristics of spray dried granules are studied. On the other hand, the effect of air pressure and nozzle diameter on the morphology and properties of freeze dried granules was evaluated. The influence of solids loading of the starting suspensions has been also studied. It has been demonstrated that these processing parameters have practically no influence on the granules morphology and properties, and the only parameter determining the granules characteristics is the solids content of the suspensions, either in the spraying or in the freezing process. Spray drying leads to a monomodal distribution with higher granule size, while freeze drying produces more porous granules, with a bimodal intragranular distribution. The flowability of spray-dried powder is better than that of the freeze-dried powder. As a result, the characteristics of the spray-dried powder suit better the requirements of a feedstock targeted to obtain coatings by plasma thermal spraying whereas freeze drying can produce high porosity, softer granules.
\end{abstract}


Keywords: A. Drying, A. Suspensions, B. Microstructure- prefiring, B. Porosity, D. $\mathrm{Al}_{2} \mathrm{O}_{3}, \mathrm{D}$. $\mathrm{TiO}_{2}$

\section{Introduction}

The development of nanostructured materials has become one of the most topical directions in advanced materials science as they have demonstrated to provide unusual properties compared with their submicrometer and micrometer counterparts. ${ }^{1}$ However, handling of nanoparticles is difficult and hazardous due to their volatility and the subsequent inhalation risks. One of the most extended routes to allow handling of nanoparticulate systems is the production of free-flowing agglomerates from colloidal suspensions subjected to a controlled drying process, such as spray or freeze drying. Moreover, the possibility to prepare nanoparticle granules by spray-drying that have a good flowability and a size that minimizes respiratory intake without inducing additional hard agglomerates could provide a route to safe handling of nanoparticles. $^{2}$

For the production of nanostructured granules the dispersion and manipulation of the nanoparticles is a key step. The characteristics of the suspension determine the morphology of the granules and then, the properties of the final ceramic product. Many studies have reported the dispersion and stability of suspensions of nanosized ceramic powders, like alumina, ${ }^{3}$ titania, ${ }^{4-6}$ and many others, ${ }^{7,8}$ focusing the effect of deflocculant concentration and $\mathrm{pH}$ on the rheological properties of differently prepared suspensions.

The granulation of nanoparticles is receiving a growing interest for the fabrication of nanostructured bulk materials with dense, fine-grained microstructures as reported elsewhere. ${ }^{7,9}$ But also for the production of nanostructured coatings by plasma techniques as atmospheric plasma spraying (APS), which requires the reconstitution of starting nanopowders into a sprayable size since nanoparticles cannot be directly deposited because of their low mass and their poor flowability. ${ }^{10-122}$

A well-recognised method to reconstitute the nanoparticles is spray-drying. ${ }^{13}$ One popular configuration in industrial spray drying consists on the preparation of a suspension that is fed 
into the drying chamber, and atomized by pumping it at high pressure through a pressure multinozzle array, after that the upward spiralling droplets encounter hot air which is fed through a diffuser into the chamber (counter-current to the droplets). ${ }^{144}$ There are also co-current and mixed systems, together with different atomization modes (rotary atomizer, pressure nozzles, two-fluid nozzles) ${ }^{15}$ Regardless the configuration and atomization mode of the spray dryer, it is always necessary to prepare and optimise the nanopowder suspensions in order to obtain homogeneous spray-dried granules with high apparent density.

Another technique for the granulation of nanoparticles is freeze drying. This technique is receiving great attention nowadays for the synthesis of nanosized powders from inorganic salts and for the manufacture of porous bodies by a freeze-casting process. The preparation of granules by this technique was developed with the objective of avoiding the migration of pressing aids to the granule surface. ${ }^{16}$ However, it is very limited as compared to spray drying. A main feature of freeze-drying as a granulation method is that the obtained granules have high porosity and so, very light granules can be produced. ${ }^{17-19}$ The porosity and consequently, the density of granules are controlled by the solid loading of the suspensions, whereas the size distribution of the granules is a function of the viscosity and the solid content of the suspension, the flow rate employed for spraying and the pressure of the applied gas. ${ }^{18,20}$

In this work commercial suspensions of colloidal alumina and titania have been used, as well as a mixture of both prepared to a weight ratio of $87 / 13$, in order to compare the two selected granulation methods, spray drying and freeze drying, and the physicochemical characteristics of the obtained granules such as their morphology, surface area, and size distribution as a function of the suspension preparation conditions. The influence of processing parameters (i.e. nozzle diameter, solids content, temperature and air pressure) on the granule characteristics has been also studied.

\section{Experimental}

\subsection{Starting raw materials characterisation}


Two commercial suspensions were employed in this study: a colloidal suspension of alumina (VP Disp. W630X, Degussa-Evonik, Germany) and a colloidal suspension of titania (AERODISP $^{\circledR}$ W740X, Degussa-Evonik, Germany), labelled as A and T, respectively. These are suspensions in water of the well-known powders AluC and P25, respectively, of the same supplier, and have a typical solids content of $\sim 10$ vol.\% and $\mathrm{pH}$ values of $\sim 4$ and $\sim 7$ for alumina and titania, respectively. AluC is a reference nanosized powder of $\gamma-\mathrm{Al}_{2} \mathrm{O}_{3}$ with a surface area of $100 \mathrm{~m}^{2} / \mathrm{g}$, and a particle diameter of $\sim 14 \mathrm{~nm}$, according to the supplier. P25 nanopowder is a reference $\mathrm{TiO}_{2}$ standard material that has been widely used elsewhere. It contains anatase and rutile phases in a ratio of about $3: 1^{21}$ and has a surface area of $49 \mathrm{~m}^{2} / \mathrm{g}$, and a BET particle diameter of $\sim 21 \mathrm{~nm}$. The main physicochemical characteristics of the commercial suspensions, as provided by the supplier, are shown in other studies. ${ }^{6,133}$ The starting suspensions were mixed to obtain the mixture $\mathrm{Al}_{2} \mathrm{O}_{3} / \mathrm{TiO}_{2}$ (suspension AT) with relative weight ratio of $87 / 13$ and maintaining always the total solids content to $10 \mathrm{vol} . \%$. In order to study the influence of solids loading, well-dispersed $\mathrm{Al}_{2} \mathrm{O}_{3}$ and $\mathrm{TiO}_{2}$ nanoparticles suspensions with higher solids content (15 vol.\%) were prepared by dispersing the nanopowder in distilled water containing a polyacrylic dispersant (DURAMAX D-3005, Rohm \& Haas, USA). Finally, these two suspensions were appropriately mixed to obtain a 15 vol.\% of nanoparticle $\mathrm{Al}_{2} \mathrm{O}_{3}$ $13 \mathrm{wt} \% \mathrm{TiO}_{2}$ suspension (ATC).

\subsection{Colloidal behaviour characterisation}

The colloidal behaviour of the nanosuspensions was studied by measuring the zeta potential as a function of $\mathrm{pH}$ using a Zetasizer NanoZS instrument (Malvern, UK), based in the laser Doppler velocimetry technique.

Different dilutions were tested to measure zeta potential with the best accuracy, which was reached for a concentration of alumina of $0.01 \mathrm{wt} \%$, and a concentration of titania of 0.005 $\mathrm{wt} \%$, using always $\mathrm{KCl} 0.01 \mathrm{M}$ as an inert electrolyte. $\mathrm{pH}$ values were determined with a $\mathrm{pH}-$ meter (716 DMS Titrine, Metrohm, Switzerland) and were adjusted with $\mathrm{HCl}$ and $\mathrm{KOH}$ solutions $(0.1$ and $0.01 \mathrm{M})$. These diluted aqueous suspensions were also used to determine the 
particle size distribution by dynamic light scattering using the same equipment employed for zeta potential measurements.

\subsection{Rheological study}

The rheological behaviour of all colloidal suspensions (the commercial A and T, and the mixtures AT and ATC) was determined using a rheometer (Haake RS50, Thermo, Karlsruhe, Germany) operating at controlled shear rate (CR) by loading the shear rate from 0 to $1000 \mathrm{~s}^{-1}$ in 5 minutes, maintaining at $1000 \mathrm{~s}^{-1}$ for 1 minute and uploading from 1000 to 0 in 5 minutes. The measurements were performed at $25^{\circ} \mathrm{C}$ using a double-cone and plate system.

\subsection{Granulation}

Granulation of the suspensions of each oxide and the mixture was performed by two drying techniques: spray drying and freeze drying. Spray-dried granules were obtained from the three diluted nanosuspensions (A, T and AT, $10 \mathrm{vol} \%$ ) in a spray dryer (Mobile Minor, Gea Niro, Denmark) with a drying capacity of $7 \mathrm{~kg}$ water/h. ${ }^{2,5,6,13}$ The spray dryer operates at countercurrent through a two-fluid atomization mode. This two-fluid nozzle atomization is achieved pneumatically by high-velocity compressed air impacting the liquid feed. The standard diameter of the nozzle used for spray drying was $2 \mathrm{~mm}$. The inlet air temperature and nozzle air pressure were maintained at $340{ }^{\circ} \mathrm{C}$ and $8.10^{4} \mathrm{~Pa}$ respectively. Additional tests with a smaller nozzle diameter $(1 \mathrm{~mm})$, higher pressure $\left(2.10^{5} \mathrm{~Pa}\right)$ and lower temperature $\left(250{ }^{\circ} \mathrm{C}\right)$ were performed with the AT suspension for comparison purposes. An approximate suspension flow rate of 0.064 $\mathrm{L} / \mathrm{min}$ was used throughout the experiments.

In the case of freeze-drying process ${ }^{22}$ all the studied suspensions: A, T, AT and ATC were sprayed over liquid nitrogen $\left(-196{ }^{\circ} \mathrm{C}\right)$. Different nozzles (with diameters of 1.0, 1.5 and 2.0 $\mathrm{mm}$ ) and aid air pressure of $5.10^{4}$ and $1.10^{5} \mathrm{~Pa}$ were used. The frozen suspensions were introduced into the freeze dryer (CRYODOS-50, Telstar, Spain) for $24 \mathrm{~h}$. The condenser temperature was $-50{ }^{\circ} \mathrm{C}$ and the conditions of the storage camera were $20^{\circ} \mathrm{C}$ and $5 \mathrm{~Pa}$. 
Granule size distributions were measured by laser diffraction (Mastersizer S, Malvern, UK). Measurements were performed after 5 minutes agitation, but the effect of the agitation in an ultrasounds bath was also studied in order to check whether the granules are broken during dispersion stage or not. Hence, granule size distribution was measured also for granules dispersed for 1 and 5 min in an ultrasounds bath. Agglomerate apparent density was calculated from powder tapped density by assuming a theoretical packing factor of 0.6 , which is characteristic of monosize and spherical particles. ${ }^{23}$

Granules flowability was evaluated in terms of Hausner ratio, which is determined by directly dividing the powder tapped density and the apparent density of the loosely packed powder bed. This method was chosen because it is quite simple and leads to reliable and reproducible findings as previously reported. ${ }^{5,6,13}$ Besides, the authors, in a still unpublished work, have observed good correlation between Hausner ratios and flow factors obtained by Jenike cell testing. The apparent yield pressure, $\mathrm{P}_{\mathrm{y}}$, of some of the agglomerates was determined from the compaction diagram as reported elsewhere. ${ }^{24} \mathrm{P}_{\mathrm{y}}$ is believed to be a measure of the granule strength.

The porosity of granules was measured by Mercury Intrusion Porosimetry, MIP (AutoPore IV 9500, Micromeritics, USA). Surface areas were measured by single point $\mathrm{N}_{2}$ adsorption (Monosorb MS-13, Quantachrome Co., USA). Finally, a field emission environmental scanning electron microscope, FEG-ESEM (QUANTA 200FEG, FEI Company, USA) equipped with an energy-dispersive X-ray spectrometer (EDAX Genesis) and a field emission scanning electron microscope, FE-SEM (Hitachi S-4700, Type I, Japan) equipped with an energy-dispersive Xray spectrometer (EDAX Hitachi, Japan) were used to study the granules microstructure.

\section{Results and discussion}

\subsection{Stability of colloidal suspensions}

Figure 1 shows the variation of zeta potential as a function of $\mathrm{pH}$ for both colloidal suspensions. As it can be seen the isoelectric points occur at $\mathrm{pH}$ values of near 10 for $\mathrm{Al}_{2} \mathrm{O}_{3}$ and below $\mathrm{pH} 6$ for the $\mathrm{TiO}_{2}$ suspension. On one hand, the isoelectric point of alumina is slightly 
higher than that obtained when dispersing the AluC alumina powder in water. ${ }^{25,26}$ On the other hand, the colloidal suspension of titania has the isoelectric point at $\mathrm{pH} \sim 6$, whereas the dry $\mathrm{P} 25$ titania powder dispersed in water gives an isoelectric point of near 7, slightly higher than that obtained for the commercial suspension. ${ }^{5,6}$ These differences in the colloidal behaviour of the commercial suspensions with respect to the suspensions prepared from the equivalent dry powders should be related to the presence of additives used for the stabilisation of the commercial ones. The thermogravimetric analyses of the dry powders reveal a weight loss of around $5 \%$ and $2.5 \%$ for $\mathrm{A}$ and $\mathrm{T}$ powders, respectively, and higher for the dried suspensions ( $7 \%$ and $4.5 \%$, respectively) thus demonstrating the presence of organic additives in the commercial suspensions that can change the colloidal behaviour.

From these curves it can be expected that heterocoagulation would occur when mixing both suspensions to prepare the mixture AT between $\mathrm{pH}$ values ranging from 6 to 10 . The natural $\mathrm{pH}$ of the mixture was around 4.3. At this $\mathrm{pH}$ a good dispersion can be obtained since both materials have the same charge sign.

\subsection{Rheological study}

The rheological behaviour was measured for the two commercial suspensions at their natural $\mathrm{pH}$. Mechanical homogenisation was required to obtain an alumina/titania nanosuspension of weight ratio $87 / 13$. The flow curves of the diluted suspensions and the concentrated mixture are shown in figure 2. The viscosities of the diluted suspensions are very low and exhibit a Newtonian behaviour, especially that of titania with a viscosity of $\sim 2 \mathrm{mPa}$.s. The viscosity of alumina suspension and AT mixture is practically the same $(\sim 7 \mathrm{mPa} . \mathrm{s})$ since alumina is the major phase of the mixture. These low viscosities are suitable for the subsequent granulation (spray-drying or freeze-drying) processes. The flow curve of the concentrated suspension shows a pseudoplastic behaviour with a small thixotropic cycle, and as expected, its viscosity is higher than that of AT suspension but it is also suitable for both granulation processes.

\subsection{Reconstitution of nanopowders by spray-drying and freeze-drying}


In a first step, the influence of different processing parameters on freeze-drying process was studied. The studied variables included two solids content suspensions (AT and ATC), three different nozzle diameters and two air pressures. The results of the average granules size are presented in Table 1, which demonstrates that among the considered variables, the only parameter with a clear influence in the size distribution is the solids loading of the suspension. In the case of 10 vol.\% suspension (AT), no significant differences were found in the range of applied pressures and nozzle diameters (between 1.0 and $2.5 \mathrm{~mm}$ ). However, for the suspension with higher solids loading (ATC) the granules have higher average size and the distribution curves show an asymmetric peak or a bimodal curve, as it can be seen in figure 3. In addition, for the concentrated suspensions, the average size increases with both the pressure and the diameter of the nozzle, and the distribution curves show that a reagglomeration of the granules occurs when the sonication time is high $(5 \mathrm{~min})$, probably as a consequence of the activation of surfaces.

The spray drying variables were also studied in order to determine the best spray drying performance. The effect of solids loading was reported in a previous work, in which the granule size distribution and the morphology of spray dried AT and ATC suspensions were studied. ${ }^{13}$ The granules obtained from the concentrated suspension displayed a narrower (more uniform) size distribution and a slightly coarser granule mean size than those of the diluted suspension. In addition the granules display a more spherical profile and uniform sizes, whereas deformed granules with the presence of smaller agglomerates inside the hole of the larger ones were more visible in the diluted sample. Therefore, solid loading has a great influence on the granules size and morphology. The present paper will focus on the effect of processing parameters excluding those related to the suspension itself. 
Table 2 compares the average sizes $\left(D_{90}, D_{50}\right.$ and $\left.D_{10}\right)$, measured for the granules obtained by spray drying of AT suspension as a function of several processing parameters, such as pressure, temperature and nozzle diameter. Unexpectedly, it seems that spraying parameters, in particular nozzle diameter and spraying air pressure do not have a great influence on the granule sizes. In this two-fluid nozzle atomization, agglomerate size is controlled by varying the nozzle flow ratio between atomizing gas and feed. However this effect was not observed in these experiments when varying the nozzle pressure probably due to the low solids concentration (10 vol.\%) and viscosity of the feeding suspensions meanwhile the feed rate was kept constant throughout the experiments. On the contrary, increasing nozzle pressure and/or decreasing nozzle diameter gave rise to a higher amount of dry droplets stuck on the inner spray dryer walls leading to decreased operation output and impairing the size and morphology of the resulting agglomerates. Thus to remove these stuck agglomerates a $400 \mu \mathrm{m}$ mesh sieving had to be carried out. Besides, when the spraying temperature was changed no significant differences were either observed in granules morphology, particularly with regard to the effect of the temperature on the donut-shape morphology (for the sake of simplicity only FEG-ESEM micrographs of selected samples are shown below). This was again probably related to the low solids content and viscosity of the used suspensions. Also in this case the temperature increasing resulted in higher agglomerates wall sticking.

The difficulty in spray drying scale-up accounts for the scarce effect observed of spraying parameters on the resulting spray dry powders characteristics together with the increasing agglomerates wall sticking problems when changing these spraying parameters. ${ }^{15}$ Thus, constrains related to pilot equipment (height and volume of the drying chamber) and feed pumping (viscosity and flow) do not allow to carry out a 
systematic approach in which the spraying parameters can be modified accordingly. In this way, standard spraying conditions are to be chosen so that spray dry powders with good properties can be obtained meanwhile the wall sticking problem is minimized.

Taking into account these results, a solids loading of 10 vol.\%, a nozzle diameter of $1 \mathrm{~mm}$ and an applied pressure of $5.10^{3} \mathrm{~Pa}$ were selected as the general freeze drying conditions to compare the characteristics of the granules. Similarly, spray drying conditions for further experiments were a nozzle diameter of $2 \mathrm{~mm}$, a temperature of $240{ }^{\circ} \mathrm{C}$ and a pressure of $8.10^{4} \mathrm{~Pa}$. By using these conditions the amount of agglomerates stuck on the spray dryer walls could be minimised. Hence nanosuspensions of $\mathrm{A}, \mathrm{T}$ and the mixture AT were used to compare spray drying and freeze drying performance at the standard conditions set out above.

Figure 4 shows the morphology of the granules of the three compositions obtained by spray drying and observed by FEG-ESEM. All the granules are micron sized but there are strong differences both in the size distribution and in the shape. As it can be seen the granules obtained for spray dried alumina are big and have nearly spherical shapes, with small granules attached to bigger ones. Titania granules present a wide distribution of sizes and have an irregular shape far from the spherical shape of typical spray dried granules. These granules are deformed as if they had been plastically distorted during drying. From the picture it can be seen that there is a bimodal distribution of granules, probably related to the presence of broken granules. Finally, the AT granules are spherical and some of them exhibit a hole at the surface with a clear tendency to the formation of donut-shaped agglomerates with a broad and continuous size distribution.

Granule size distributions measured by laser diffraction (Figure 5) confirmed the micrometer size range of the spray-dried agglomerates. Strong differences are also observed among the different spray-dried powders. In the case of alumina a sharp Gaussian peak is obtained with an average diameter value of $58 \mu \mathrm{m}$ and a very low intensity broad coil below $20 \mu \mathrm{m}$ until $1 \mu \mathrm{m}$. The homogenisation with 1 or 5 min US seems not to affect to the size distribution, maintaining 
the average particle size in the range 50-60 $\mu \mathrm{m}$. Titania granules show a strong peak centred at around $90 \mu \mathrm{m}$, and a very small broad peak at $\sim 0.3 \mu \mathrm{m}$, probably associated to broken granules. When dispersed in the US bath for 1 minute, the bimodality maintains and the small broad fraction of lower size increases in intensity and shifts slightly to lower sizes $(<0.2 \mu \mathrm{m})$, thus suggesting that granules are breaking down. After 5 minutes in the US bath, the size distribution changes and a new distribution with three peaks is obtained. The intense peak occurring at larger sizes disappears and two broad, low intensity peaks appear in the size range between 10 and $100 \mu \mathrm{m}$. In addition, the intensity of the peak centred at $\sim 0.5 \mu \mathrm{m}$ becomes stronger. This demonstrates that the spray-dried granules of titania are very brittle and are destroyed by the US bath. Finally, the AT agglomerates displayed a Gaussian monomodal granule size distribution with an average diameter of $\sim 60 \mu \mathrm{m}$. When dispersing with the US bath, the Gaussian distribution slightly deforms in the lower size region. That means that AT granules are stronger and are not practically affected by the dispersion in the US bath. This is an advantage as it facilitates handling and mixing.

As in the case of spray-dried granules, freeze-dried ones were characterised by FE-SEM, as it is shown in figure 6 for the three starting powders. A first observation for all materials is that freezing leads to much lower size distribution than spraying, more than expected from the difference between nozzle diameters. The FE-SEM pictures show a broad distribution with small granules and a small fraction of larger sizes, although the maximum size of the granules is higher for alumina than for titania. The granules of the mixture AT look like those of the alumina major phase although it seems that the number of big agglomerates has increased. In figure 7 the granule size distribution of all three types of granules before and after mixing in the US bath are plotted. The alumina freeze-dried granules show a monomodal distribution with a distorted Gaussian shape, where the coil of the lower fraction is broader and the mode is located at $<30 \mu \mathrm{m}$, this being in good agreement with FE-SEM observations. The dispersion in the US bath makes the curve to be more symmetric and the values of the average size and the mode decrease, the mode being by 20 and $10 \mu \mathrm{m}$ after 1 and $5 \mathrm{~min}$ of US, respectively. In the case of 
freeze-dried titania granules there is a masked bimodal distribution, with a strong peak at $<2$ $\mu \mathrm{m}$ and a broad coil at larger sizes, centred at 10-15 $\mu \mathrm{m}$. After dispersion with US bath, the curve maintains practically the same, although it seems to shift very slightly to lower sizes. In the case of the AT granules, the shape of the distribution curves is the opposite to that of the titania granules, with a stronger peak at large granule sizes $(\sim 40 \mu \mathrm{m})$ and a broad coil toward low sizes. The dispersion with US maintains the general shape of the curve although it becomes less broad and the mode reduces to $<15 \mu \mathrm{m}$. It can be stated that the granule size for freezing is much lower than in the case of spray-drying, and then the effect of US bath is quite different, especially in the case of titania where the granules are very small in diameter $(<2 \mu \mathrm{m})$ and then they are not destroyed by the US. This is also true for the mixture, in which the shape of the distribution curve maintains although the size reduces. This suggests that although the spraydried granules exhibit an apparently higher fragility than that of the freeze-dried ones, it must be taken into account that the size of the granules achieved during the drying operation is much higher.

Surface area values of samples obtained by both methods are presented in table 3 . These measurements do not account for the different pore structure existing between spray dried and freeze dried granules. In order to evaluate the different pore structure it is necessary to consider the volume of pores.

Pore volume results measured by MIP can be seen in figure 8 and table 3 . These results demonstrate that pore volume of freeze dried samples is higher than that of spray dried ones. As it can be observed, pore volume curves present also a different behaviour depending on the drying process. In all cases there is an intergranular porosity, with characteristic pore diameters ranging from $<5$ to $200 \mu \mathrm{m}$, in the same order of magnitude of the granules. However, there are interesting differences in the intragranular porosity between samples obtained by spray drying and freeze drying, as it can be clearly observed in the pore volume distribution curve shown in figure 9. Spray-dried samples exhibit a single peak for a pore diameter similar to the particle size $(\sim 15 \mathrm{~nm})$, whereas freeze dried samples exhibit a bimodal pore distribution, with a peak at 
the same range of diameters of that found for spray drying (by $20 \mathrm{~nm}$ ) and another broad, intense peak with an average diameter of around $1 \mu \mathrm{m}$. This contribution to porosity is due to ice sublimation. This effect has been also observed in the synthesis of nanoalumina powders by freeze drying using salts solutions. ${ }^{27}$

From the cumulative curves of AT granules plotted in figure 8, the values of the different contributions to pore volume and diameter can be evaluated, as shown in table 4 . The intergranular pore volume is higher for freeze drying, but the strongest difference occurs in the intragranular pore distribution, where a large volume, characteristic peak appears. Figure 10 shows a high magnification micrograph of the surface aspect of an AT granule obtained by freeze drying. This picture is representative of the microstructure obtained by freezing and demonstrates that pores have a polyhedral morphology, far from the typical spherical shape of pores due to air entrapment. The size of these pores is in agreement with the measured pore size peak shown in figure 9. These features are characteristic of the freeze-drying process, where ice templating leads to the formation of columns that have to be removed during sublimation.

Table 5 summarizes some of the main properties of the powders produced by both methods, i.e., the Hausner ratio and the agglomerate apparent density which were calculated as set out above. Despite the rough assumption of monosized, spherical granules, in particular for the freeze-dried agglomerates, it can be clearly observed that the apparent density of the freezedried granules is much lower than that of spray-dried powders (2-3 times) which confirms the large porosity retained in the freeze-dried granules which was previously determined by porosimetry test and observed by SEM. The poor flowability (higher value of Hausner ratio) of freeze-dried powders in comparison with spray-dried ones is due to the fact that the low gravitational forces associated with highly porous agglomerates cannot counterbalance the high frictional forces due to small, less spherical agglomerates. ${ }^{23,28}$ In the case of the spray-dried powders, the irregular shape of $\mathrm{T}$ sample granules together with a higher amount of finer agglomerates in this powder result in worse flowability than that of the A and AT samples.

Finally, the apparent yield pressure, $\mathrm{P}_{\mathrm{Y}}$, of AT spray drying and freeze drying powders was determined from the compaction diagram. The values are also shown in table 5. As expected 
from the porosity (or apparent density) of the different agglomerates, spray dried agglomerates, which are much denser than freeze dried ones show much higher yield pressure (granule strength). Similar differences between the granule strength of spray and freeze drying agglomerates were previously reported by Moritz and Nagy ${ }^{18}$. However these authors found lower granule strength probably due to the fact that they used a different method based on the direct determination of single granule strength. In addition, the values of yield pressure obtained from the AT spray dried agglomerates are between 2-3 times higher than those of microstructured, spray dried agglomerates as reported elsewhere. ${ }^{24}$ Thus nanostructured agglomerates give rise to an increased number of particle contacts which result in stronger granules.

The poor flowability of freeze dried powders limits many of their potential applications as nanoestructured powders. In this sense, some of the methods of producing finely structured coatings by atmospheric plasma spraying (APS) involve the use of nanostructured powder feedstocks. Researchers have reported that the apparent density of the agglomerates of APS feedstock powders can range widely from less than $1000 \mathrm{~kg} / \mathrm{m}^{3}$ to $2000 \mathrm{~kg} / \mathrm{m}^{3}{ }^{12}$ High flowability (Hausner ratio $<1.25)^{13}$ is also required for even flow of the agglomerates through the plasma torch. Thus, the spray-dried powders obtained in this work easily accomplish with these requirements but the freeze-dried powders are far from doing that. Hence, for this application the apparent density of the freeze-dried agglomerates are to be clearly enhanced by means of the following actions: 1) increasing the solids content of the suspension to be freezedried, 2) filling the voids with a temporary binder if porous structures are to be obtained, and 3) performing a thermal treatment of the agglomerates so as to partially reduce their porosity. Research is now in progress concerning these proposed actions.

\section{Conclusions}

In this work the spray drying and freeze drying of commercial suspensions of colloidal alumina and titania as well as a mixture of both prepared to a weight ratio of $87 / 13$ have been 
carried out, in order to compare the two granulation methods and the physicochemical characteristics of the obtained granules as a function of the suspension preparation conditions. For the preparation of the mixture the colloidal suspensions were mixed at their natural $\mathrm{pH}$ to get good dispersion. All suspensions showed a Newtonian behaviour with very low viscosities suitable for the subsequent granulation (spray drying or freeze drying) processes.

All the spray-dried granules are micron sized but there are strong differences both in the size distribution and in the shape. Titania granules present a wider distribution of sizes and display an irregular shape far from the spherical shape of typical spray-dried granules. Alumina and alumina/titania granules are stronger than those of titania and are less affected by the dispersion in the US bath.

Freezing leads to much lower size distribution than spraying, more than expected from the difference between nozzle diameters. Although the spray-dried granules exhibit an apparently higher fragility than the freeze-dried ones, it must be taken into account that the size of the granules achieved during the spray-drying operation is much higher.

With regard to pore size distribution of the powders, in all cases there is an intergranular porosity, with characteristic pore diameters ranging from $<5$ to $200 \mu \mathrm{m}$. However, there are interesting differences in the intragranular porosity between samples obtained by spray drying and freeze drying. Freeze-drying samples exhibit a bimodal intragranular pore distribution, with a peak at the same range of diameters of that found for spray drying (by $20 \mathrm{~nm}$ ) and another broad, intense peak with an average diameter of around $1 \mu \mathrm{m}$ due to ice sublimation. These last pores have a polyhedral morphology since ice templating leads to the formation of columns that have to be removed during sublimation.

The estimated apparent density of the freeze-dried granules is much lower than that of spraydried powders (2-3 times) which confirms the high porosity retained in the freeze-dried granules. This porosity results in much softer granules when compared with spray dried agglomerates. In addition, this porosity, together with the high frictional forces due to small, less spherical agglomerates in comparison with spray-dried ones, are the reasons for the poor flowability of the freeze-dried powders. This flowability could be improved through the 
increase of agglomerate apparent density. The freeze-dried granules can be used to produce high porosity materials.

\section{Acknowledgements}

This work has been supported by Spanish Ministry of Science and Innovation and the European Regional Development Fund (MAT2009-14144-C03-01, MAT2009-14369-C02-01 and PID600200-2009-5), and by the Institute of Small and Medium-sized Enterprise (IMPIVA) of the Autonomous Government of Valencia.

\section{References}

1. Moriarty P. Nanostructured materials. Rep. Prog. Phys. 2001; 64: 297-381.

2. Faure B, Lindeløv JS, Wahlberg M, Adkins N, Jackson P, Bergström L. Spray drying of $\mathrm{TiO}_{2}$ nanoparticles into redispersible granules. Powder Technol. 2010; 203: 384-388.

3. Jailani F, Franks GV, Healy TW. $\zeta$ potential of nanoparticle suspensions: effect of electrolyte concentration, particle size, and volume fraction. J. Am. Ceram. Soc. 2008; 91 : $1141-1147$.

4. Fazio S, Guzmán J, Colomer MT, Salomoni A, Moreno R. Colloidal stability of nanosized titania aqueous suspensions. J. Eur. Ceram. Soc. 2008; 28: 2171-2176.

5. Vicent M, Sánchez E, Santacruz I, Moreno R. Dispersion of $\mathrm{TiO}_{2}$ nanopowders to obtain homogeneous nanostructured granules by spray-drying. J. Eur. Ceram. Soc. 2011; 31: 1413-1419.

6. Vicent M, Sánchez E, Moreno A, Moreno R. Preparation of high solids content nanotitania suspensions to obtain nanostructured spray-dried powders for atmospheric plasma spraying. J. Eur. Ceram. Soc. 2012; 32: 185-194.

7. Santacruz I, Annapoorani K, Binner J. Preparation of high solids content nano zirconia suspensions. J. Am. Ceram. Soc. 2008; 91: 398-405.

8. Santacruz I, Nieto MI, Binner J, Moreno R. Wet forming of concentrated nano $\mathrm{BaTiO}_{3}$ suspensions. J. Eur. Ceram. Soc. 2009; 29: 881-886. 
9. Moritz T, Nebelung M, Oswald M. Development of dense, fine-grained bulk ceramics from nanosized zirconia powder using pressing technologies. Ceramic forum international: cfi. $2007 ; \mathbf{8 4}, 43-48$.

10. Lee $\mathrm{C}$, Choi $\mathrm{H}$, Lee $\mathrm{C}$, Kim $\mathrm{H}$. Photocatalytic properties of nano-structured $\mathrm{TiO}_{2}$ plasma sprayed coating. Surf. Coat. Technol. 2003; 173, 192-200.

11. Sánchez E, Cantavella V, Bannier E, Salvador MD, Klyastina E, Morgiel J, Grzonka J, Boccaccini AR. Deposition of $\mathrm{Al}_{2} \mathrm{O}_{3}-\mathrm{TiO}_{2}$ nanostructured powders by atmospheric plasma spraying. J. Therm. Spray Technol. 2008; 17: 329-337.

12. Fauchais P, Montavon G, Bertrand G. From powders to thermally sprayed coatings. $J$. Therm. Spray Technol. 2010; 19: 56-80.

13. Sánchez E, Vicent M, Moreno A, Salvador MD, Klyastina E, Bonache V, Santacruz I, Moreno R. Preparation and spray-drying of nanoparticle $\mathrm{Al}_{2} \mathrm{O}_{3}-\mathrm{TiO}_{2}$ suspensions to obtain nanostructures coatings by APS. Surf. Coat. Technol. 2010; 205: 987-992.

14. Negre F, Sánchez E. Advances in spray-dried pressing powder processes in tile manufacture. In: Henkes VE, Onoda, GY, Carty WM, editors. Science of Whitewares. Ohio: American Ceramic Society; 1996, p. 169-181.

15. Spray drying handbook. $5^{\text {th }}$ edition. K. Master. Ed. Longman Scientific \& Technical, 1991

16. Lyckfeldt O, Kack D, Rundgren K. Pressing and sintering developments of Freeze Granulated $\mathrm{Si}_{3} \mathrm{~N}_{4}$ materials. Ceram Eng Sci Proc 2003; 24: 331-336.

17. Uchida N, Hiranami T, Takada S, Uematsu K. Spray-freeze-dried granules for ceramics fabrication. Am. Ceram. Soc. Bull. 2002; 81: 57-60.

18. Moritz T, Nagy A. Preparation of super soft granules from nanosized ceramic powders by spray freezing. J. Nanopart. Res. 2002; 4: 439-448.

19. Yokota T, Takahata Y, Katsuyama T, Matsuda Y. A new technique for preparing ceramics for catalyst support exhibiting high porosity and high heat resistance. Catalysis Today 2001; 69: 11-15

20. Rundgren K, Lyckfeldt O, Sjostedt M. Improving powders with freeze granulation. Ceramic Industry 2003; 153: 40-44. 
21. Ohno T, Sarukawa K, Tokieda K, Matsumura M. Morphology of a $\mathrm{TiO}_{2}$ Photocatalyst (Degussa P-25) Consisting of Anatase and Rutile Crystalline Phases. J. Catal. 2001; 203: $82-86$.

22. Tallón C, Moreno R, Nieto MI. Synthesis of $\gamma-\mathrm{Al}_{2} \mathrm{O}_{3}$ nanopowders by freeze-drying. Mater. Res. Bull. 2006; 41: 1520-1529.

23. Amorós JL, Blasco A, Enrique JE, Negre F. Características de polvos cerámicos para prensado. Bol. Soc. Esp. Ceram. Vidr. 1987; 26: 31-37.

24. Amorós JL, Cantavella V, Jarque JC, Feliú C. Fracture properties of spray-dried powder compacts: Effect of granule size. J. Eur. Ceram. Soc. 2008; 28: 2823-2834.

25. Hazan $\mathrm{Y}$ de, Werner D, Z'graggen $\mathrm{M}$, Groteklaes $\mathrm{M}$, Graule. Homogeneous Ni-P/ $\mathrm{Al}_{2} \mathrm{O}_{3}$ nanocomposite coatings from stable dispersions in electroless nickel baths. J. Colloid Interface Sci. 2008; 328: 103-109.

26. Schilde C, Mages-Sauter C, Kwade A, Schuchmann HP. Efficiency of different dispersing devices for dispersing nanosized silica and alumina. Powder Technol. 2011; 207: 353-361.

27. Tallón C, Yates M, Moreno R, Nieto MI. Porosity of freeze-dried $\gamma-\mathrm{Al}_{2} \mathrm{O}_{3}$ powders. Ceram. Int. 2007; 33: 1165-1169.

28. Jong de AAH, Hoffmann AC, Finkers HJ. Properly determine powder flowability to maximize plant output. Chem. Eng. Prog. 1999; 95: 25-34. 


\section{Figure captions}

Figure 1. Variation of zeta potential with $\mathrm{pH}$ for commercial suspensions of titania $(\bullet)$ and alumina

Figure 2. Flow curves of diluted suspensions of alumina (A), titania (T) and the mixture (AT) compared to the concentrated (ATC) suspension

Figure 3. Granule size distribution of granules obtained by freeze-drying from dilute (AT) and concentrated (ATC) suspensions, $\mathrm{d}_{\text {nozzle }}=2.5 \mathrm{~mm}, \mathrm{p}=5.10^{4} \mathrm{~Pa}, 1 \mathrm{~min} \mathrm{US}$

Figure 4. FEG-ESEM micrographs showing the morphology of granules of $A, T$ and AT obtained by spray-drying

Figure 5. Granules size distribution of A, T and AT obtained by spray-drying

Figure 6. FE-SEM micrographs showing the morphology of granules of A, T, and AT obtained by freeze-drying

Figure 7. Granules size distribution of A, T and AT obtained by freeze-drying

Figure 8. Cumulative pore volume curves of $\mathrm{A}, \mathrm{T}$ and $\mathrm{AT}$ obtained by spray-drying and freezedrying

Figure 9. Intragranular pore volume distribution curves of AT obtained by spray-drying and freeze-drying

Figure 10. FE-SEM micrograph showing the porous microstructure of an AT granule obtained by freeze-drying 


\section{Tables}

Table 1. Average granule size obtained by freeze drying at different conditions, from AT and ATC measured after 1 min US

\begin{tabular}{|c|c|c|c|c|}
\hline $\begin{array}{c}\text { Nozzle diameter } \\
(\mathrm{mm})\end{array}$ & $\begin{array}{c}\text { Pressure } \\
\left(\mathrm{x} 10^{-4} \mathrm{~Pa}\right)\end{array}$ & $\begin{array}{c}\text { Solid content } \\
(\text { vol.\% })\end{array}$ & $\begin{array}{c}\text { Average granule size } \\
(\mu \mathrm{m})\end{array}$ & Comments \\
\hline \multirow{2}{*}{1.0} & 5 & 10 & 6.8 & \\
\cline { 2 - 5 } & \multirow{2}{*}{10} & 15 & 11.0 & $\begin{array}{c}\text { Asymmetric } \\
\text { peak }\end{array}$ \\
\cline { 2 - 5 } & & 10 & 7.1 & $\begin{array}{c}\text { Asymmetric } \\
\text { peak }\end{array}$ \\
\hline 1.5 & 5 & 15 & 17.3 & \\
\hline \multirow{2}{*}{2.5} & 5 & 10 & 7.7 & Bimodal \\
\cline { 2 - 5 } & & 15 & 6.5 & 26.6 \\
\hline
\end{tabular}

Table 2. Average sizes measured for the AT granules obtained by spray drying with different spraying conditions (no US was applied)

\begin{tabular}{|c|c|c|c|c|}
\hline \multicolumn{2}{|c|}{ Sample } & \multicolumn{3}{c|}{ Average granule sizes $(\mu \mathrm{m})$} \\
\cline { 3 - 5 } & AT & $\mathrm{D}_{10}$ & $\mathrm{D}_{50}$ & $\mathrm{D}_{90}$ \\
\hline $\begin{array}{c}\text { Spray-dried } \\
(\mathrm{d}=2 \mathrm{~mm} \text { mtandard P and T) }\end{array}$ & AT-higher P & 71 & 178 \\
\hline \multirow{2}{*}{$\begin{array}{c}\text { Spray-dried } \\
(\mathrm{d}=1 \mathrm{~mm})\end{array}$} & AT-standard P and T & 30 & 79 & 170 \\
\cline { 2 - 5 } & AT-lower T & 38 & 110 & 202 \\
\hline
\end{tabular}

Table 3. Surface area and pore volume of samples obtained by spray drying and freeze drying

\begin{tabular}{|c|c|c|c|}
\hline \multicolumn{2}{|c|}{ Sample } & Surface area $\left(\mathrm{m}^{2} / \mathrm{g}\right)$ & Total pore volume $\left(\mathrm{cm}^{3} / \mathrm{g}\right)$ \\
\hline \multirow{2}{*}{$\begin{array}{c}\text { Spray-dried } \\
(\mathrm{d}=2 \mathrm{~mm})\end{array}$} & $\mathrm{A}$ & 82 & 0.9872 \\
\cline { 2 - 4 } & $\mathrm{T}$ & 51 & 0.8440 \\
\cline { 2 - 4 } & AT & 90 & 1.0975 \\
\hline \multirow{2}{*}{$\begin{array}{c}\text { Freeze-dried } \\
(\mathrm{d}=1 \mathrm{~mm})\end{array}$} & $\mathrm{A}$ & 110 & 3.4847 \\
\cline { 2 - 4 } & $\mathrm{T}$ & 48 & 2.8385 \\
\cline { 2 - 4 } & AT & 89 & 3.3398 \\
\hline
\end{tabular}


Table 4. Porosity parameters of AT samples obtained by spray drying and freeze drying

\begin{tabular}{|c|c|c|c|c|c|c|}
\hline \multirow{2}{*}{ Sample } & \multicolumn{4}{|c|}{ Intragranular porosity } & \multicolumn{2}{c|}{ Intergranular porosity } \\
\cline { 2 - 7 } & $\mathrm{dp}(\mathrm{nm})$ & $\mathrm{Vp}\left(\mathrm{cm}^{3} / \mathrm{g}\right)$ & $\mathrm{dp}(\mu \mathrm{m})$ & $\mathrm{Vp}\left(\mathrm{cm}^{3} / \mathrm{g}\right)$ & $\mathrm{dp}(\mu \mathrm{m})$ & $\mathrm{Vp}\left(\mathrm{cm}^{3} / \mathrm{g}\right)$ \\
\hline $\begin{array}{c}\text { Spray } \\
(\mathrm{d}=2 \mathrm{~mm})\end{array}$ & $\sim 15$ & 0.34 & - & - & $4-200$ & 0.76 \\
\hline $\begin{array}{c}\text { Freeze } \\
(\mathrm{d}=1 \mathrm{~mm})\end{array}$ & $\sim 20$ & 0.46 & $\sim 1$ & 1.72 & $4-200$ & 1.16 \\
\hline
\end{tabular}

Table 5. Some important powder characteristics of spray-dried and freeze-dried samples

\begin{tabular}{|c|c||c|c|c|}
\hline \multicolumn{2}{|c|}{ Sample } & Hausner ratio & $\begin{array}{c}\text { Agglomerate } \\
\text { apparent density } \\
\left(\mathrm{kg} / \mathrm{m}^{3}\right)\end{array}$ & $\begin{array}{c}\text { Apparent yield } \\
\text { pressure, } \mathrm{P}_{\mathrm{Y}}(\mathrm{MPa})\end{array}$ \\
\hline \multirow{2}{*}{$\begin{array}{c}\text { Spray-dried } \\
(\mathrm{d}=2 \mathrm{~mm})\end{array}$} & $\mathrm{A}$ & $1.12 \pm 0.03$ & 1505 & \\
\cline { 2 - 5 } & $\mathrm{T}$ & $1.20 \pm 0.03$ & 1870 & \\
\cline { 2 - 5 } & $\mathrm{AT}$ & $1.13 \pm 0.03$ & 1415 & \\
\hline \multirow{2}{*}{$\begin{array}{c}\text { Freeze-dried } \\
(\mathrm{d}=1 \mathrm{~mm})\end{array}$} & $\mathrm{A}$ & $1.28 \pm 0.03$ & 485 & \\
\cline { 2 - 5 } & $\mathrm{T}$ & $1.30 \pm 0.04$ & 935 & 0.75 \\
\cline { 2 - 5 } & $\mathrm{AT}$ & $1.33 \pm 0.03$ & 505 & \\
\hline
\end{tabular}




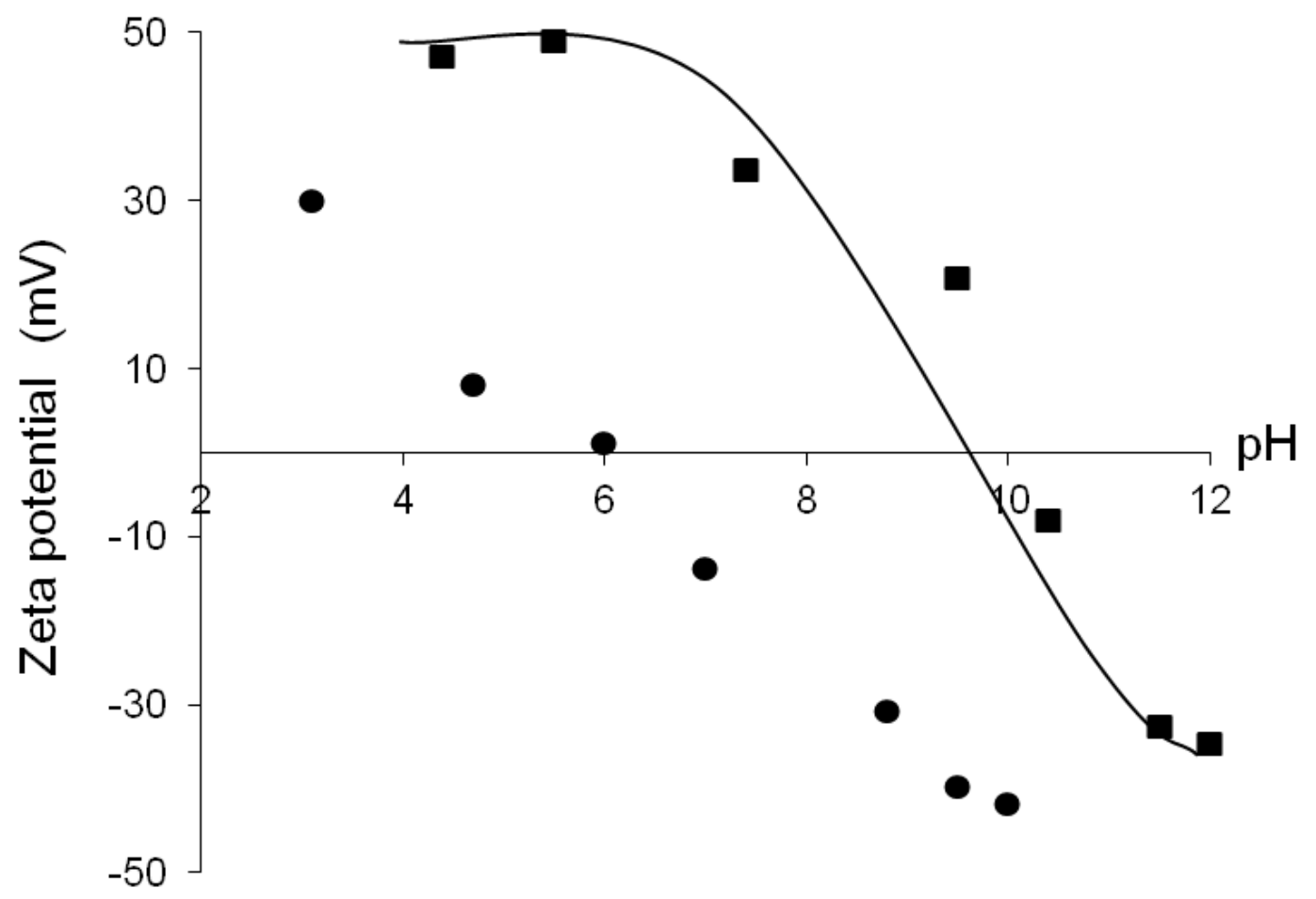

Figure 1 


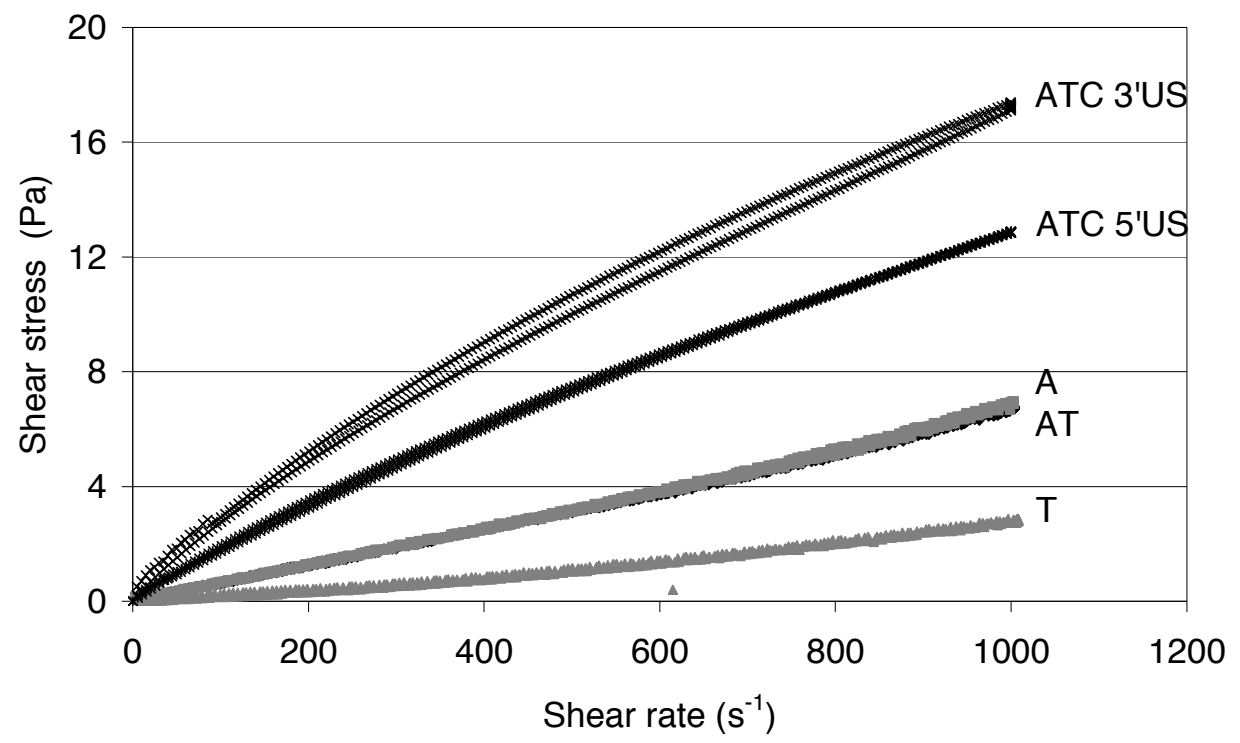

Figure 2 


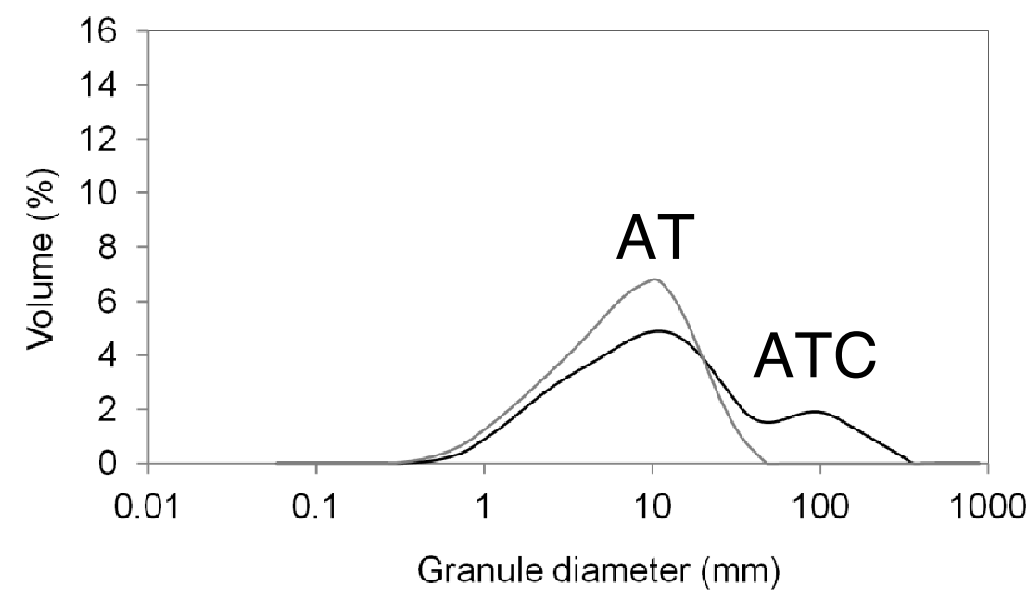

Figure 3 

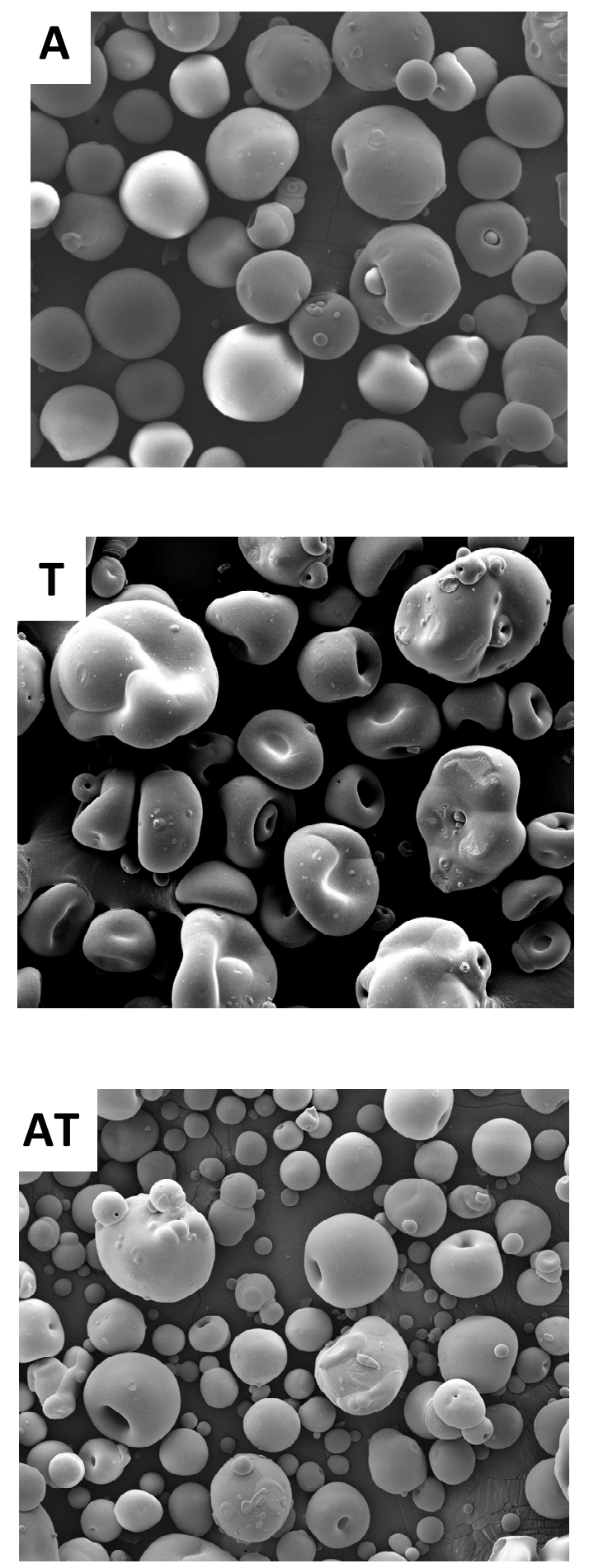

Figure 4 

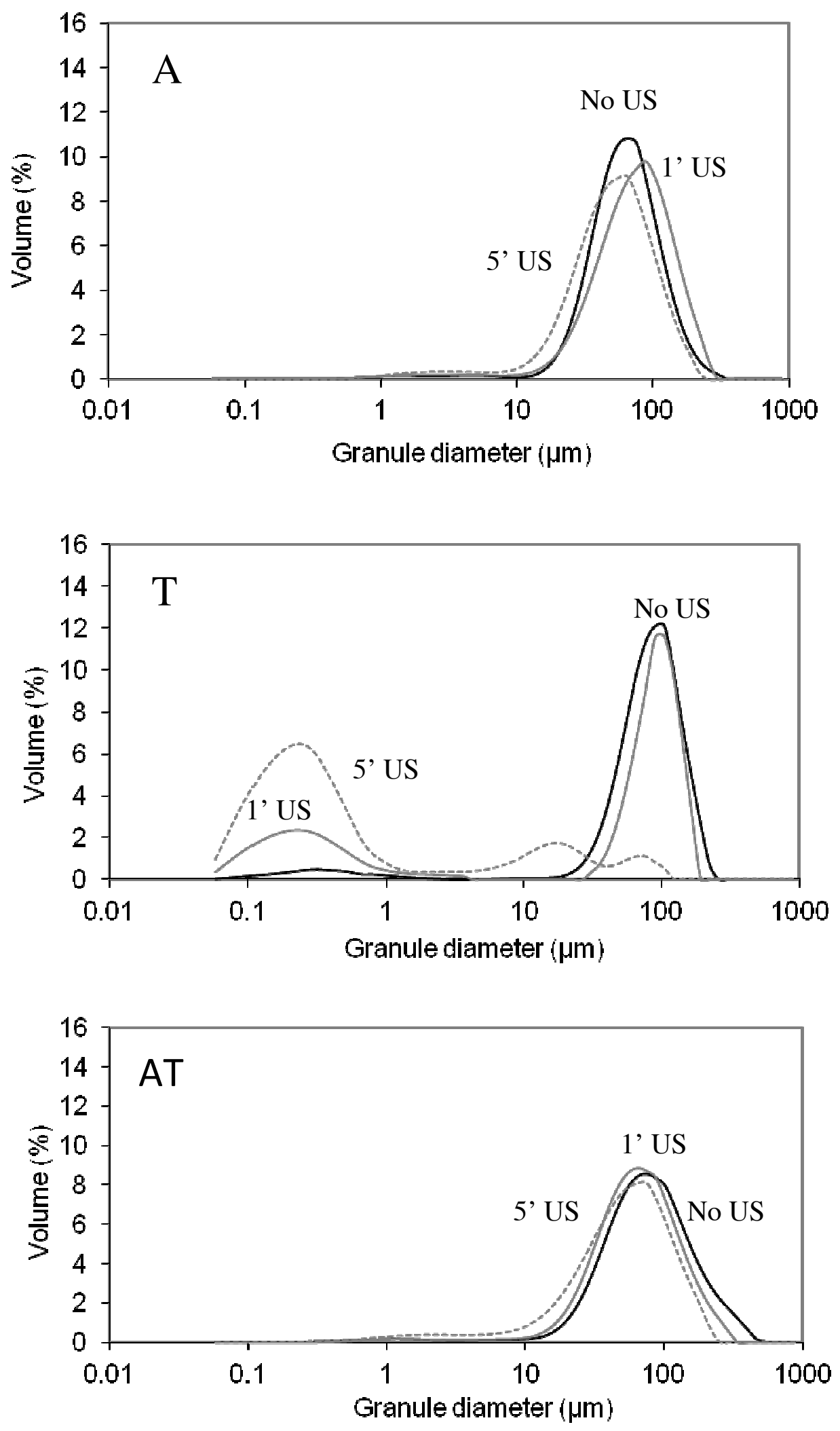

Figure 5 

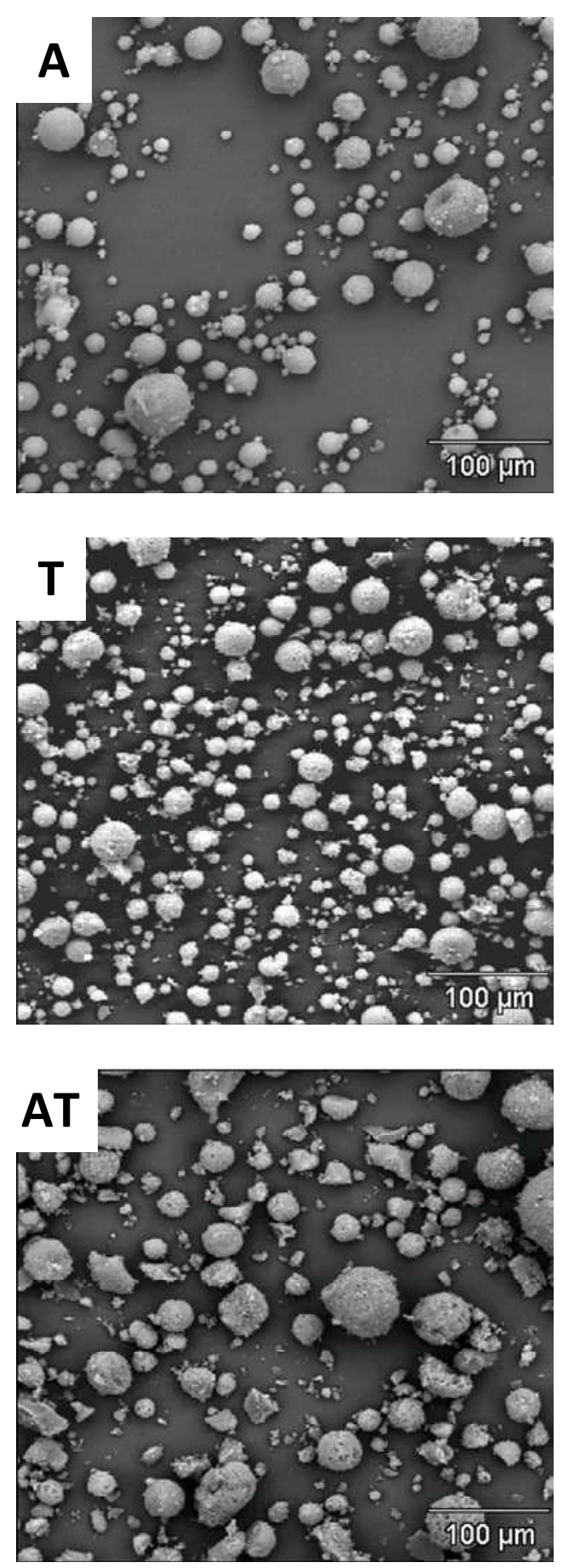

Figure 6 

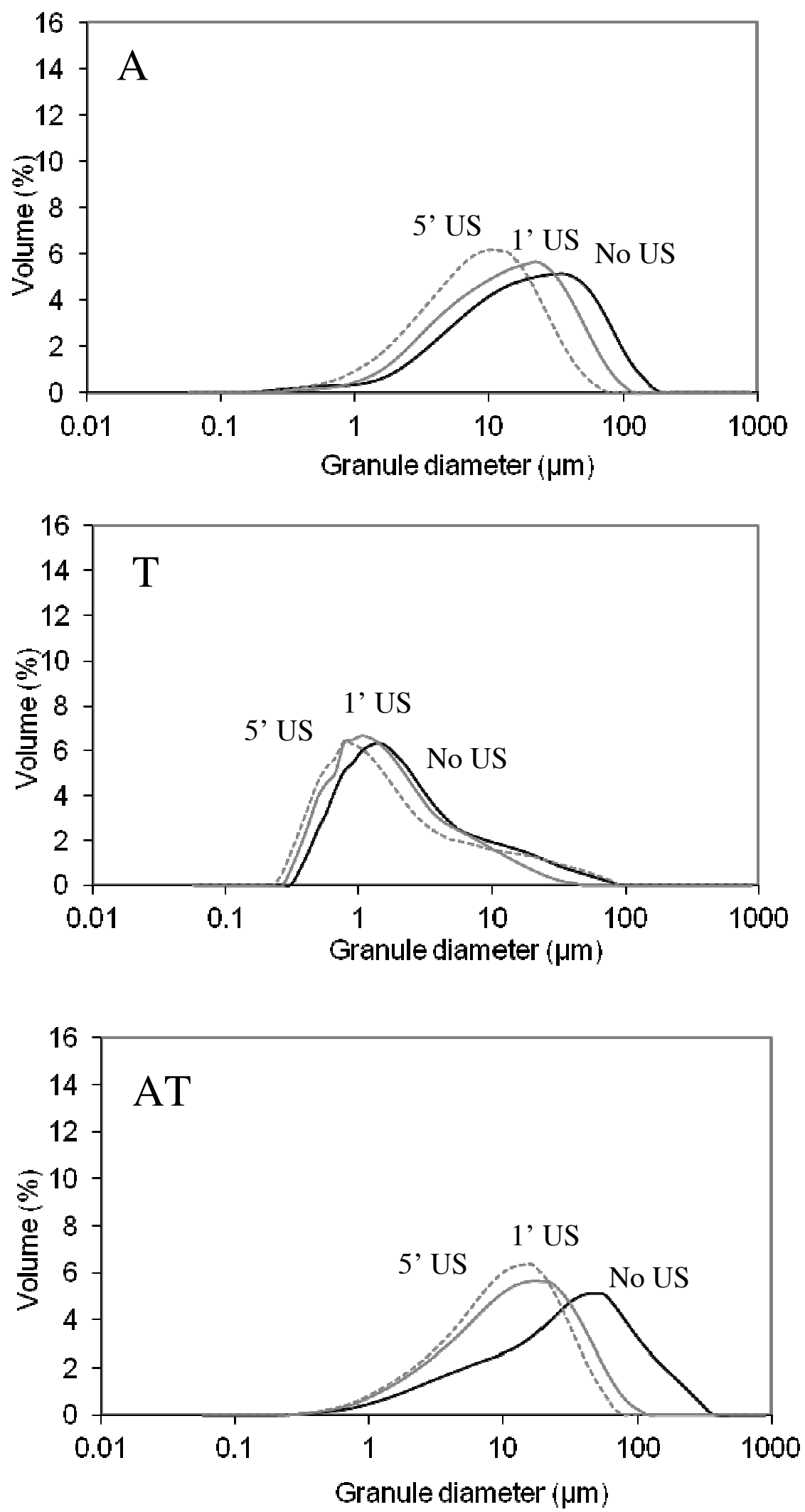

Figure 7 


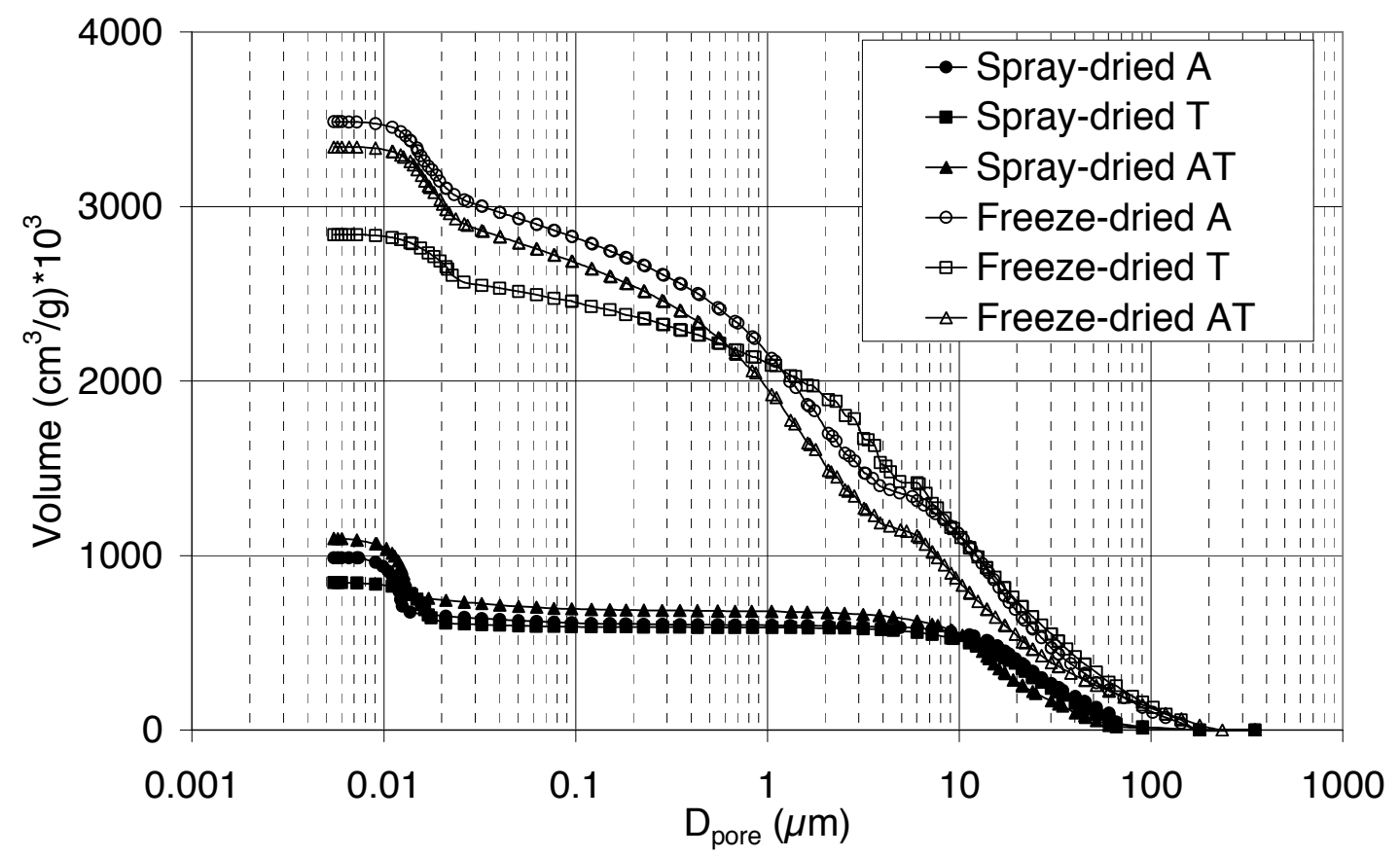

Figure 8 


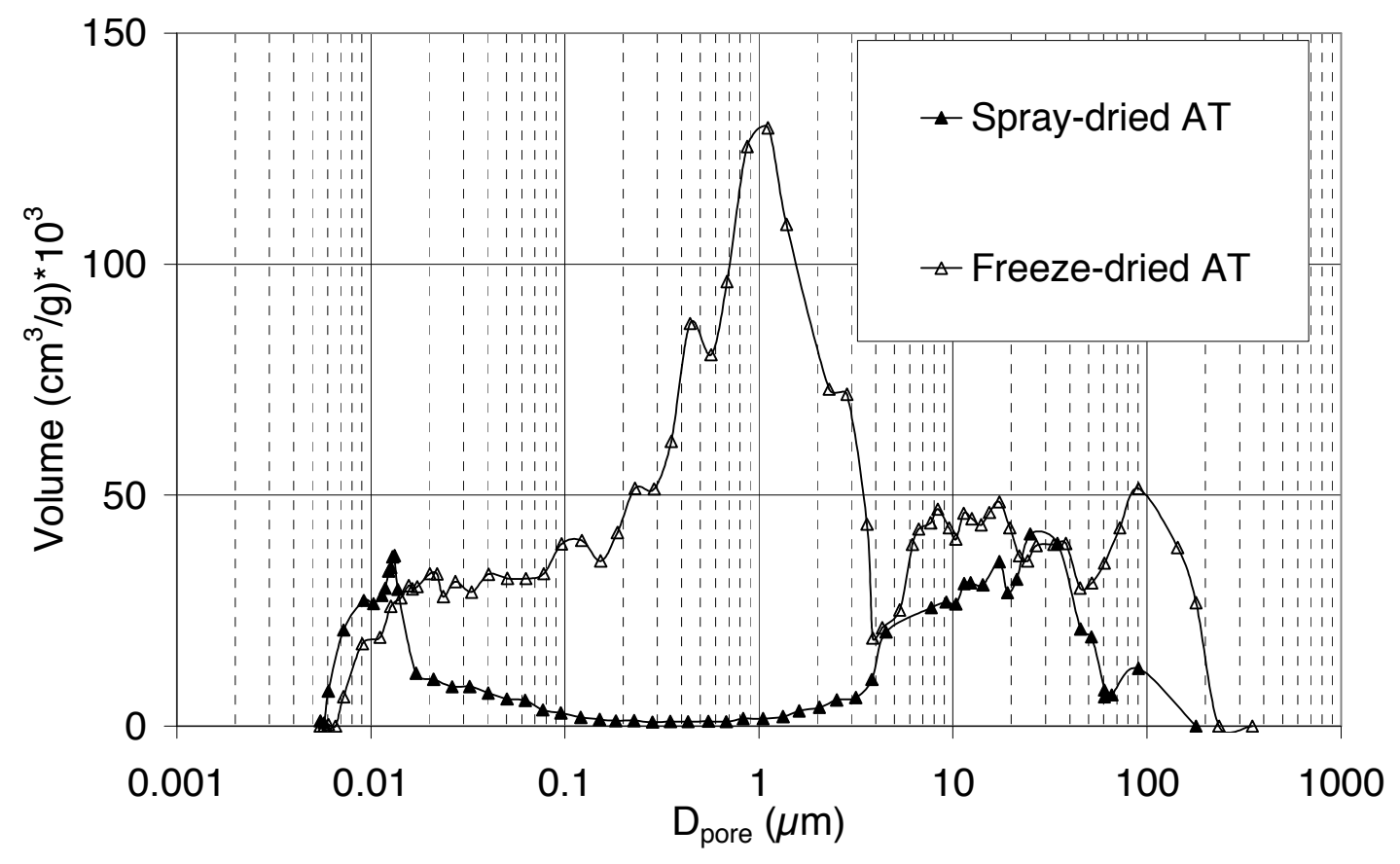

Figure 9 


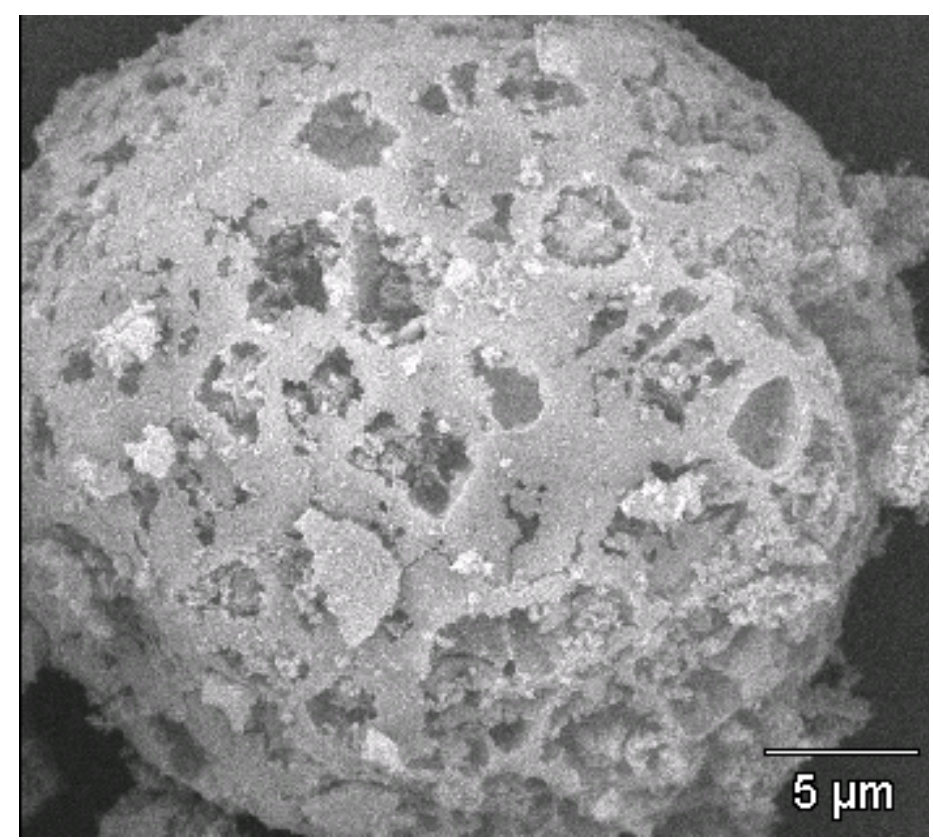

Figure 10 